\title{
Estimation of Alkaloids and Antibacterial Activity of Aconitum spicatum Bruhl Stapf from Manaslu Conservation Area
}

\author{
Sajan L. Shyaula ${ }^{1}$, Ash B. Ngakushi ${ }^{2}$, Bijaya L. Maharjan ${ }^{1}$ and Mangala D. Manandhar ${ }^{1}$ \\ ${ }^{1}$ Nepal Academy of Science and Technology \\ Khumaltar, Lalitpur \\ ${ }^{2}$ Tri-Chandra Multiple Campus \\ Tribhuvan University, Kathmandu \\ e-mail: shyaulasajan@gmail.com
}

\begin{abstract}
Aconitum spicatum is one of the deadly poisonous and highly valued medicinal plant. It is a national prioritized herb among 30 national priority herbs listed by the government of Nepal for their development, research and cultivation. The acute toxicity of the extract of this plant appeared to be directly related to the alkaloid content. The amount of total alkaloid of A. spicatum collected from Manaslu conservation area was calculated to be $1.7 \%$ by spectrophotometric method based on Dragendorff's reagent. In-vitro evaluation of the crude extract of plant rhizomes using agar well diffusion assay against eight bacteria, Staphylococcus aureus, Escherichia coli, Schigella flexneri, Pseudomonas aeruginosa, Salmonella typhi, Salmonella paratyphi, Salmonella typhimurium and Klebsiella pneumonia, displayed potential antibacterial activity. The diethyl ether fraction was the most effective against all pathogenic microbes with minimum bacterial concentration value $3.125-6.25 \mathrm{mg} / \mathrm{ml}$.
\end{abstract}

Key words: Aconitum spicatum, antibacterial, Manaslu conservation area, total alkaloid

\section{Introduction}

Aconitum spicatum is one of the highly valued medicinal plants which is in trade from Nepal to India in a huge quantity (Olsen 1998). It belongs to the family Ranunculaceae and is widely distributed in the alpine and subalpine regions. The plants are usually perennial or biennial herbs, often with stout leafy stems, bulbs or creeping rhizomes. Leaves are mostly cauline, lobed, rarely divided and dentate. Flowers are simple or branched recemes. The tubers of Aconitum are used in the herbal medicines only after processing. The tuberous roots are commonly applied for various diseases, such as rheumatic fever, painful joints and some endocrinal disorders. A. spicatum as a traditional herb, its extracts have been employed in analgesic balms, sedatives and febrifuges in Tibet (FCCAS 1979). Considering its high medicinal value, A. spicatum was collected from Manaslu conservation area in 2010..

Manaslu Conservation Area is one of the most remote areas of Nepal, situated in upper region of Gorkha district. Nepal Academy of Science and Technology
(NAST) has initiated a long term research activities at Manaslu conservation area. It is resourceful in terms of the highly valued medicinal plants. As a part of ongoing investigation on the highly valuable medicinal plants, Aconitum was selected for determination of its alkaloid content and its biological activities. It mainly consists of C-20 diterpenoid and C-19 norditerpenoid alkaloids, bisnorditerpenoids and also phenolic and its glycoside compounds (Atta-ur-Rahman et al. 1995). The diterpenoid alkaloids can be divided into the following two broad categories on the basis of various substituents, which apparently affect both the chemical and pharmacological properties of these alkaloids. Alkaloids that have hexacyclic C19-skeleton and alkaloids that bear a C20-skeleton. C19-diterpenoid alkaloids comprise of the toxic ester moiety and can be further divided into four groups, aconitine, lycoctonine, pyrodelphinine and heteratisine classes on the basis of various carbon skeletons. C20Diterpenoid alkaloids occur as esters but are relatively nontoxic. These alkaloids have been further classified into three basic types such as atisine, vetachine and 
delnudine. Spicatine A and spicatine B were some reported norditerpenoids from $A$. spicatum by chinese group (Gao et al. 2005). The determination of total alkaloid content is thus essential for standardization of this plant. It is determined by spectrophotometric method based on using Dragendorff's reagent. The toxicity of Aconitum, mainly derives from the diester diterpene alkaloids and can be decomposed into less or non toxic derivatives through different processing methods (Judith et al. 2009).

After processing, Aconitum species are usually mixed with other plants and used as a medicine in Ayurvedic and Traditional Chinese Medicine systems rather than the single component (Shyaula 2011). However, limited studies on antimicrobial activities have been done in Aconitum species (Ahmad et al. 2008). Even though pharmacological industries have produced a number of new antibiotics, resistance to these drugs by microorganisms has increased (Gold et al. 1996). The use of plant extract and its constituents can be of great significance in the therapeutic use. Aconitum is traditionally used for infected wounds to counteract the effect of edema which prompted us to carry out antimicrobial activity (Manandhar 2002). Evaluation of biological activities on Aconitum can have important role on discovery of the rational drugs. Here, the antibacterial property of A. spicatum (locally Amchis called Chenduk) collected from Prokh, Manaslu conservation area has been described.

\section{Methodology}

\section{Equipment}

For the evaporation process Hahn Shin Hahnvapor rotary evaporator (made in Korea) was used. The UV/Vis spectrophotometer 6715 was from Jenway/ UK and Centrifuge FD 80-2 was from China.

\section{Solvent and chemicals}

The chemicals used were purchased from Merck, Qualigens, Himedia and S. D. fine-chem. All the chemicals used were of the analytical grade.

\section{Plant materials}

The rhizomes of $A$. spicatum were collected from Prokh Village development committee at the altitudes of 3,800-3,900 m situated in Manaslu Conservation Area. The plant was identified at National Herbarium Laboratory, Godawari, Lalitpur, Nepal. It was chopped into small pieces and air dried. The air dried material was then grinded into fine powder for extraction.

\section{Extraction process}

The powdered sample (695 g) was then extracted with $1 \% \mathrm{HCl} / \mathrm{Methanol}$. The solvent was completely evaporated from the crude extract and it was then subjected to solvent-solvent extraction process to obtain hexane, diethyl ether, dichloromethane (neutral, basic and acidic) and ethyl acetate fractions.

\section{Spectrophotometric Method of Estimation of Alkaloids Total alkaloid content in the extract was estimated by spectrophotometric method based on using Dragendorff's reagent. The amount of bismuth present was estimated after precipitating the alkaloids with Dragendorff's reagent (Sreevidya et al. 2003).}

Preparation of Dragendorff's reagent: The Dragendorff's reagent was prepared by mixing solutions A and B. (solution A, $0.8 \mathrm{~g}$ bismuth nitrate pentahydrate in $40 \mathrm{ml}$ of distilled water and $10 \mathrm{ml}$ glacial acetic acid; solution B, 8.0 g potassium iodide in $20 \mathrm{ml}$ distilled water).

Preparation of standard bismuth nitrate solution: Bismuth nitrate stock solution was made by dissolving $10 \mathrm{mg} \mathrm{Bi}\left(\mathrm{NO}_{3}\right)_{3} \cdot 5 \mathrm{H}_{2} \mathrm{O}$ in $5 \mathrm{ml}$ of concentrated nitric acid and diluting to $100 \mathrm{ml}$ with distilled water.

Thiourea: $3 \mathrm{~g}$ thiourea was dissolved in $100 \mathrm{ml}$ distilled water.

Disodium sulfide: $1 \mathrm{~g}$ Disodium sulfide was dissolved in $100 \mathrm{ml}$ distilled water.

Extraction of A. spicatum: $10 \mathrm{~g}$ coarsely powdered of root of $A$. spicatum was extracted with $50 \mathrm{ml}, 2 \%$ methanolic acetic acid for $1.5 \mathrm{~h}$ and the extract was diluted to $100 \mathrm{ml}$ with $2 \%$ methanolic acetic acid.

The calibration curve was obtained by preparing series of dilutions of bismuth nitrate pentahydrate stock solution and constant amount of thiourea solution. The absorbance value of the yellow solution was measured at $435 \mathrm{~nm}$. For determination of total alkaloid content in plant material, the extract was first treated with Dragendorff's reagent. The precipitate thus obtained was then treated with disodium sulfide. The brownish black precipitate formed was then dissolved in concentrated nitric acid and further treated with thiourea and absorbance was measured at $435 \mathrm{~nm}$. The amount of bismuth present in the solution was calculated by multiplying the absorbance values with the factor. The factor is obtained from the standard curve which is constant for different concentrations.

Factor $=$ Concentration/ absorbance 


\section{Bacterial strains}

Eight bacterial strains, Staphylococcus aureus, Shiegella flexneri (ATCC 25923), Pseudomonas aeruginosa (ATCC 27853), Salmonella paratyphi, S. typhi, S. typhimurium (ATCC 14038) and Klebsiella pneumoniae (ATCC 13883) were used for antimicrobial activity of Aconitum extracts.

\section{Antimicrobial activity of various fractions}

The antibacterial assay of different fractions of the plant extracts were evaluated by agar well diffusion method as given by Dingle (Dingle et al. 1953). The method evaluated the antibacterial activity of the plant extracts with the determination of zone of inhibition (ZOI). The human pathogenic bacteria used for the study were Staphylococcus aureus, Escherichia coli, Schigella flexneri, Pseudomonas aeruginosa, Salmonella typhi, Salmonella paratyphi, Salmonella typhimurium and Klebsiella pneumoniae. For antibacterial assay, the standard inoculums of each bacterial species were prepared and matched with Mac Farland 0.5 . The wells were made in the swabbed media plates with the help of sterile cork borer (diameter 4 $\mathrm{mm})$. Fifty microlitres of working solution $(50 \mathrm{mg} / \mathrm{ml}$ prepared in dimethyl sulphoxide) of the different fractions of the plant extract were loaded into the wells. The plates were then left for half an hour so as to facilitate diffusion of the extracts in the media. The plates were then incubated at $37{ }^{\circ} \mathrm{C}$ for $24 \mathrm{hrs}$ and observed for the zone of inhibition suggested by the clean area without growth around the well. The antibacterial tests of the extracts were further carried out by two fold broth dilution method so that the antibacterial activity could be quantitatively interpreted in the form of minimum inhibitory concentration (MIC) and minimum bactericidal concentration (MBC).

\section{Results and Discussion}

The plant material (695 g) extracted with $1 \% \mathrm{HCl}$ methanol by soxhlet extraction method yielded 106.43 g (15.31\%) of crude extract. The crude extract when treated with Dragendorff's reagent, it showed pink red color indicating the presence of alkaloids. On further fractionation with solvent-solvent extraction process, hexane (1.15 g), diethyl ether (4.28 g), neutral dichloromethane (2.71 g), basic dichloromethane (2.1 g), acidic dichloromethane (1.17 g) and ethyl acetate (1.2 g) were obtained. The water insoluble part of the extract was $8.23 \mathrm{~g}$ and was found to be soluble in methanol.

For estimation of the total alkaloid content, $10 \mathrm{~g}$ coarsely powdered root of $A$. spicatum was extracted with $50 \mathrm{ml}, 2 \%$ methanolic acetic acid for $1.5 \mathrm{~h}$ and the extract was diluted to $100 \mathrm{ml}$ with $2 \%$ methanolic acetic acid. The alkaloids were precipitated as complex formation by Dragendorff's reagent. The bismuth from the alkaloidal complex was then completely released by disodium sulfide. Bismuth forms a yellow bismuth complex in nitric acid medium with thiourea. The calibration graph between concentration and absorbance was linear. Because the complex formed was $1: 1$, the amount of bismuth corresponds to amount of alkaloids present. The amount of alkaloid present is calculated to be $1.7 \%$. The alkaloid content of A. spicatum from Manaslu Conservation Area was first time calculated and its content was found to be high in comparison to other species (Faugeras et al.1973).

The antibacterial activity was expressed in terms of the diameter of zone of inhibition (in $\mathrm{mm}$ ) and the results are summarized in Table 1 . S. aureus causes urinary tract infections, wound infections and food poisoning while $P$. aeruginosa causes hospital acquired infections. Salmonella sp causes typhoid and paratyphoid fever. S. flexneri causes dysentry and K. pneumoniae causes respiratory tract infections. E. coli an intestinal opportunistic pathogen causes diarrhea and urinary tract infection. The results indicated that there was variation in the inhibitory activity among the different types of extracts on the pathogens. The extracts were effective against both the Gram positive as well as Gram negative bacteria (Fig 1). The diethyl ether fraction displayed the highest antibacterial activity in all the pathogens with the zone of inhibition varying from 17 to $20 \mathrm{~mm}$. The acidic chloroform fraction was next effective fraction inhibiting five of the pathogens tested and the zone of inhibition ranged from 6 to $11 \mathrm{~mm}$. This indicated non polar fraction of Aconitum extract has greater antibacterial property. E. coli was the most sensitive among the pathogens tested. The data obtained in this study demonstrate that the possibility of use of these extracts to lower the risk of microbial infections, particularly in the intestinal and respiratory tract. 
Table 1. Antibacterial activity of different fractions of $A$. spicatum extract

\begin{tabular}{|c|c|c|c|c|c|c|c|}
\hline \multirow[t]{2}{*}{ Bacterial pathogens } & \multicolumn{7}{|c|}{ Zone of inhibition given by the extracts (mm) (Diameter of well = $4 \mathrm{~mm}$ ) } \\
\hline & Hexane & $\begin{array}{l}\text { Acidic } \\
\text { chloroform }\end{array}$ & $\begin{array}{l}\text { Basic } \\
\text { chloroform }\end{array}$ & $\begin{array}{l}\text { Neutral } \\
\text { chloroform }\end{array}$ & $\begin{array}{l}\text { Diethyl } \\
\text { ether }\end{array}$ & Methanol & $\begin{array}{r}\text { Ethyl } \\
\text { acetate }\end{array}$ \\
\hline Staphylococcus aureus & 6 & 6 & - & - & 20 & - & - \\
\hline Escherichia coli & - & 11 & 10 & 12 & 17 & 7 & 6 \\
\hline Schigella flexneri & - & 10 & 9 & - & 20 & - & - \\
\hline Pseudomonas aeruginosa & - & - & - & - & 17 & - & - \\
\hline Salmonella typhi & 8 & 10 & 6 & - & 20 & - & 6 \\
\hline Salmonella paratyphi & - & - & - & - & 19 & - & - \\
\hline Salmonella typhimurium & 6 & - & - & - & 18 & - & - \\
\hline Klebsiella pneumoniae & 7 & 6 & - & - & 18 & - & - \\
\hline
\end{tabular}

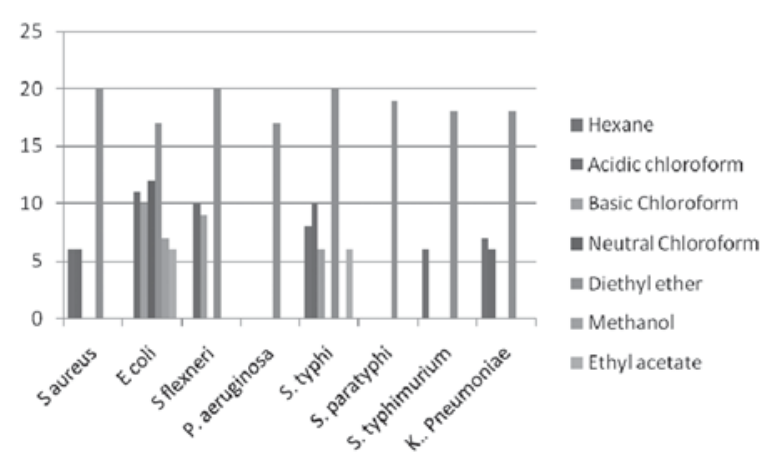

Fig. 1. Effect of different fractions of Aconitum extract on pathogenic bacterial strains

The diethyl ether fraction, being most effective one, was subjected for determination of MIC and MBC value. The extract being colored, MIC value for the tested pathogens could not be determined while the MBC value ranged from 3.125-6.25 mg/ml (Table 2). This diethyl ether fraction was specifically effective towards Salmonella typhi with MBC value $3.125 \mathrm{mg} /$ $\mathrm{mL}$.

The determination of total alkaloid content of $A$. spicatum from Manaslu Conservation Area was found to be high and its further chemical analysis is essential to identify its potent bioactive constituents.

\section{Acknowledgements}

The authors are thankful to Mr. Dorge Thakuri and Ms. Seerjana Maharjan, for collection and identification of the plant material. The present study was carried out as a part of NAST thematic research program at Manaslu Conservation Area.

Table 2. Minimum bactericidal concentration (MBC) of diethyl ether extracts of A. spicatum

\begin{tabular}{|c|c|c|c|c|c|c|c|}
\hline \multirow[t]{2}{*}{ Bacterial pathogens } & \multicolumn{6}{|c|}{ Concentration of diethyl ether extract $(\mathrm{mg} / \mathrm{ml})$} & \multirow{2}{*}{$\begin{array}{l}\text { MBC } \\
(\mathrm{mg} / \mathrm{ml})\end{array}$} \\
\hline & 25.00 & 12.50 & 6.25 & 3.12 & 1.56 & 0.78 & \\
\hline Staphylococcus aureus & - & - & - & + & + & + & 6.25 \\
\hline Escherichia coli & - & - & - & + & + & + & 6.25 \\
\hline Schigella flexneri & - & - & - & + & + & + & 6.25 \\
\hline Pseudomonas aeruginosa & - & - & - & + & + & + & 6.25 \\
\hline Salmonella typhi & - & - & - & - & + & + & 3.12 \\
\hline Salmonella paratyphi & - & - & - & + & + & + & 6.25 \\
\hline Salmonella typhimurium & - & - & - & + & + & + & 6.25 \\
\hline Klebsiella pneumoniae & - & - & - & + & + & + & 6.25 \\
\hline
\end{tabular}




\section{References}

Ahmad, M., W. Ahmad, M. Zeeshan, Obaidullah and F. Shaheen. 2008. Norditerpenoid alkaloids from the roots of Aconitum heterophyllum Wall. With antibacterial activity. Journal of Enzyme Inhibition and Medicinal Chemistry 23: 1018-1022.

Atta-ur-Rahman and M.I. Choudhary. 1995. Diterpenoid and steroidal alkaloid. Natural Product Reports 12(4): 361-379.

Dingle, J., W.W. Red and G.L. Salamons. 1953. The enzymatic degradation of pectin and other polysaccharides II: Application of cup assay method to the estimation of enzymes. Journal of Science, Food and Agriculture 4: 149-53.

Faugeras, G., J.F. Dobremez, J. Bourgeois and R.R. Paris. 1973. Aconitum from Nepal. Preliminary study of six species collected in 1972. Plantes Medicine Et Phytotherapie 7(2): 151-62.

Flora Committee of Chinese Academy of Sciences. 1979. The Chinese flora. Vol. 27. Science Press, Beijing, 219 p.
Gao, L.M., X. Wei and L. Yang. 2005. Two new norditerpenoid alkaloids from $A$. spicatum Staf. Chinese Chemical Letters 16 (4): 475-478.

Gold, S.G. and R.C. Moellering. 1996. Antimicrobial drug resistance. The New England Journal of Medicine 335: 1445-1453.

Judith, S., Z. Ming, P. Sonja and K. Brigitte. 2009. Aconitum in traditional Chinese medicine -a valuable drug or unpredictable risk. Journal of Ethnopharmcology 126: 18-30.

Manandhar, N.P. 2002. Plants and people of Nepal. Timber Press, Inc. Portland, Oregon, USA.

Olsen, C.S. 1998. The trade in medicinal and aromatic plants from central Nepal to northern India. Economic Botany 52(3): 279-292.

Shyaula, S.L. 2011. Phytochemicals, traditional uses and processing of Aconitum species in Nepal. Nepal Journal of Science and Technology 12: 171-178.

Sreevidya, N. and S. Mehrotra. 2003. Spectrophotometric method for estimation of alkaloids precipitate with Dragendorff's reagent in plant materials. Journal of AOAC International 86(6): 1124-1127. 
Nepal Journal of Science and Technology Vol. 13, No. 1 (2012) 